\title{
Unilateral synchronous papillary renal neoplasm with reverse polarity and clear cell renal cell carcinoma: a case report with KRAS and PIK3CA mutations
}

Hyun Jung Lee ${ }^{1,2}$, Dong Hoon Shin ${ }^{1,2^{*}}$, Joon Young Park ${ }^{1}$, So Young Kim', Chung Su Hwang ${ }^{1}$, Jung Hee Lee ${ }^{1}$, Jee Yeon Kim', Mee Young Sol ${ }^{1}$ and Jong Kil Nam

\begin{abstract}
Background: The presence of histologically different neoplasms in the same organ is rare in pathologic practice. We report the first case of synchronous clear cell renal cell carcinoma (clear cell RCC) and papillary renal neoplasm with reverse polarity (PRNRP) with comprehensive immunohistochemical and molecular characterization using nextgeneration sequencing (NGS).

Case presentation: A 61-year-old man was incidentally found to have a left renal mass on imaging studies performed for workup of left back pain and urine color change for 1 week. A laparoscopic left radical nephrectomy was performed. Gross examination showed lobulated masses measuring $5.6 \times 4.0 \times 3.3 \mathrm{~cm}$ in the upper to mid pole and $1.1 \times 1.0 \times 1.0 \mathrm{~cm}$ in the lower pole. Microscopic findings revealed these to be two different separate masses of clear cell renal cell carcinoma and papillary renal neoplasm with reverse polarity. NGS analyses revealed KRAS gene mutation (c.35G > T/p.G12V in exon 2) in the papillary renal neoplasm with reverse polarity, with PIK3CA gene mutation restricted to the clear cell renal cell carcinoma (c.1624G > A/p.E542K in exon 10).

Conclusions: We report here an extraordinarily rare case of synchronous renal tumors of papillary renal neoplasm with reverse polarity and clear cell renal cell carcinoma. We identified simultaneous KRAS and PIK3CA mutations in two different renal masses in the same kidney for the first time. New pathologic assessment with comparative molecular analysis of mutational profiles may be helpful for tumor studies.
\end{abstract}

Keywords: Papillary renal neoplasm with reverse polarity, Clear cell renal cell carcinoma, Multiple masses, KRAS mutation, PIK3CA mutation

\section{Introduction}

Renal cell carcinoma (RCC) is the most common solid tumor of the kidney and accounts for $2-3 \%$ of all

\footnotetext{
* Correspondence: donghshin@chol.com

'Department of Pathology, School of Medicine, Pusan National University, Yangsan, Korea

${ }^{2}$ Research Institute for Convergence of Biomedical Science and Technology, Pusan National University Yangsan Hospital, Yangsan, Korea

Full list of author information is available at the end of the article
}

malignancies in adults [1]. The most common subtypes of RCC are clear cell, papillary, and chromophobe RCC, and they account for approximately 75,10 , and $5 \%$ of cases, respectively [2]. Since 1997, papillary renal cell carcinoma has been classified into types 1 and 2 based on the morphologic findings [3]. Histologically, papillae are lined by cuboidal cells with scant basophilic cytoplasm on the fibrovascular cores in type I, whose nuclei are usually arranged in a single layer with a low

C C The Author(s). 2020 Open Access This article is licensed under a Creative Commons Attribution 4.0 International License, which permits use, sharing, adaptation, distribution and reproduction in any medium or format, as long as you give appropriate credit to the original author(s) and the source, provide a link to the Creative Commons licence, and indicate if changes were made. The images or other third party material in this article are included in the article's Creative Commons licence, unless indicated otherwise in a credit line to the material. If material is not included in the article's Creative Commons licence and your intended use is not permitted by statutory regulation or exceeds the permitted use, you will need to obtain permission directly from the copyright holder. To view a copy of this licence, visit http://creativecommons.org/licenses/by/4.0/ The Creative Commons Public Domain Dedication waiver (http://creativecommons.org/publicdomain/zero/1.0/) applies to the data made available in this article, unless otherwise stated in a credit line to the data. 
International Society of Urological Pathology (ISUP) grade. In contrast, type II is defined by nuclear pseudostratification, higher ISUP grades, and abundant eosinophilic cytoplasm. Type I has a better prognosis than type II. Most recently, 18 cases of papillary renal neoplasm with reverse polarity (PRNRP) were described by $\mathrm{Al}$ Obaidy et al. [4]. PRNRP is histologically characterized by thin branching papillae, or rarely, predominant tubules covered by bland oncocytic cells with apical lowISUP-grade nuclei.

There are a few studies in the literature describing bilateral synchronous malignant renal tumors $[5,6]$ and coexisting benign and malignant tumors in the same kidney [7]. However, clear cell RCC and PRNRP arising within the same kidney have not yet been reported in the literature. The presence of histologically different neoplasms in the same organ is rare in pathologic practice. Herein, we present the first well-described case of synchronous PRNRP and clear cell RCC with immunohistochemical and NGS analysis. We also reviewed multiple synchronous renal masses in Pusan National University Yangsan Hospital between March 2010 and January 2020.

\section{Materials and methods}

Paraffin sections were prepared (2- $\mu \mathrm{m}$ thickness) and stained using routine methods on VENTANA (Roche, Basel, Switzerland) and BOND-MAX (Leica Biosystems, Buffalo Grove, IL) autostainers with the following antibodies: AMACR (13H4, $\alpha$-methylacylcoenzyme A racemase; Agilent Technologies, Santa Clara, CA), CD10 (clone 56C6, Leica Biosystems), cytokeratin 7 (CK7; clone OV-TL 12/30, Leica Biosystems), high-molecularweight (HMW) keratin (clone 34ßE12, Agilent Technologies), TFE3 (MRQ-37, Cell Marque; Rocklin, CA), E-cadherin (clone 4A2C7; Invitrogen, Carlsbad, CA), CAIX (clone ab15086; Abcam, Cambridge, United Kingdom), GATA3 (clone L50-823, Ventana, Tucson, AZ), vimentin (clone V9, Invitrogen, Camarillo, CA), and EMA (clone E29, DAKO, Carpinteria, CA). Stained slides were scored for the presence and distribution of positive immunostaining.

DNA libraries were prepared using the NGeneBio library prep kit (NGeneBio, Seoul, Korea), enriched for $120-\mathrm{kb}$ fragments, and sequenced with a paired-end 300-bp (150 bp each) protocol using a MiSeq platform (Illumina, San Diego, CA). Targeted sequencing raw data were obtained in FASTAQ format. Raw reads were aligned against the reference human genome assembly (GRCh37/hg19) using NGeneAnalysis v1.4.4.0 software (NGeneBio). A minimum coverage of 20 reads per basepair was subsequently used for variant calling. Variants with a variant allele frequency of less than $5 \%$ were excluded. Variants outside 10 bases from exon-intron boundaries were also excluded from analysis.

\section{Case presentation}

A 61-year-old man was incidentally found to have a left renal mass on imaging studies performed for workup of left back pain and urine color change for 1 week. A computed tomographic imaging scan of the kidneys revealed an enhancing mass with central necrosis and a sub-centimeter-sized hypodense nodule. Laparoscopic left radical nephrectomy was performed.

Pathologic gross examination showed a vaguely circumscribed lobulated mass in the upper to mid pole, which measured $5.6 \times 4.0 \times 3.3 \mathrm{~cm}$. The cut surface of the mass was bright golden yellow with areas of graywhite fibrosis and hemorrhage (Fig. 1a). Apart from this main mass, a separate small nodule was present in the lower pole, which measured $1.2 \times 1.0 \times 0.6 \mathrm{~cm}$ (Fig. 1b). Both tumors were confined to the kidney, having no extension into the perinephric adipose tissue, renal sinus, renal pelvis, or Gerota fascia. Hematoxylin and eosin (H\&E)-stained sections from the larger tumor showed a well-circumscribed neoplasm composed predominantly of solid nests and lobules of large round cells with relatively monotonous round nuclei showing no mitoses and abundant granular eosinophilic cytoplasm (Fig. 1c and d). The second nodule was well-encapsulated, showing proliferation of delicate fibrovascular cores and variable numbers of macrophages. The papillary fibrovascular cores were thick and hyalinized. The tumors were cuboidal with eosinophilic cytoplasm. The nuclei were low-ISUP-grade nuclei and were arranged linearly and inverted toward the apical surface (Fig. $1 \mathrm{e}$ and $\mathrm{f}$ ). For further evaluation, immunohistochemical stains were performed. The tumor cells were positive for CD10, AMACR, CAIX, and vimentin and negative for CK7, TFE3, E-cadherin, HMW keratin and GATA3. The separate small mass was positive for CK7, GATA3, AMACR, Ecadherin, HMW keratin, and EMA and negative for CD10, vimentin, CAIX, and TFE3 (Fig. 2). AMACR was moderately positive showing blush-like staining, which was weaker than that seen in the proximal renal tubules in the separate small mass. Based on the morphology and immunohistochemical findings, a chromophobe or translocation RCC were excluded. The findings support clear cell RCC and PRNRP. The tumor in the upper pole was clear cell RCC, with pathologic stage pT1b N0 M0. The histologic grade (World Health Organization [WHO]/ISUP nuclear grade) was 3. The second tumor in the lower pole was PRNRP, its pathologic stage was pT1a N0 M0, and its histologic grade (WHO/ISUP nuclear grade) was 2 . Sarcomatoid features and necrosis were absent. The patient has been alive and well for 8 months after surgery.

NGS analysis detected a KRAS mutation in the PRNRP in the exon 2-codon 12 junction (c. $35 \mathrm{G}>\mathrm{T}$ resulting in p.G12V). A PIK3CA mutation was detected in the clear cell RCC in the exon 10-codon 542 junction (c.1624 G > A resulting in p.E542K) (Fig. 3). 


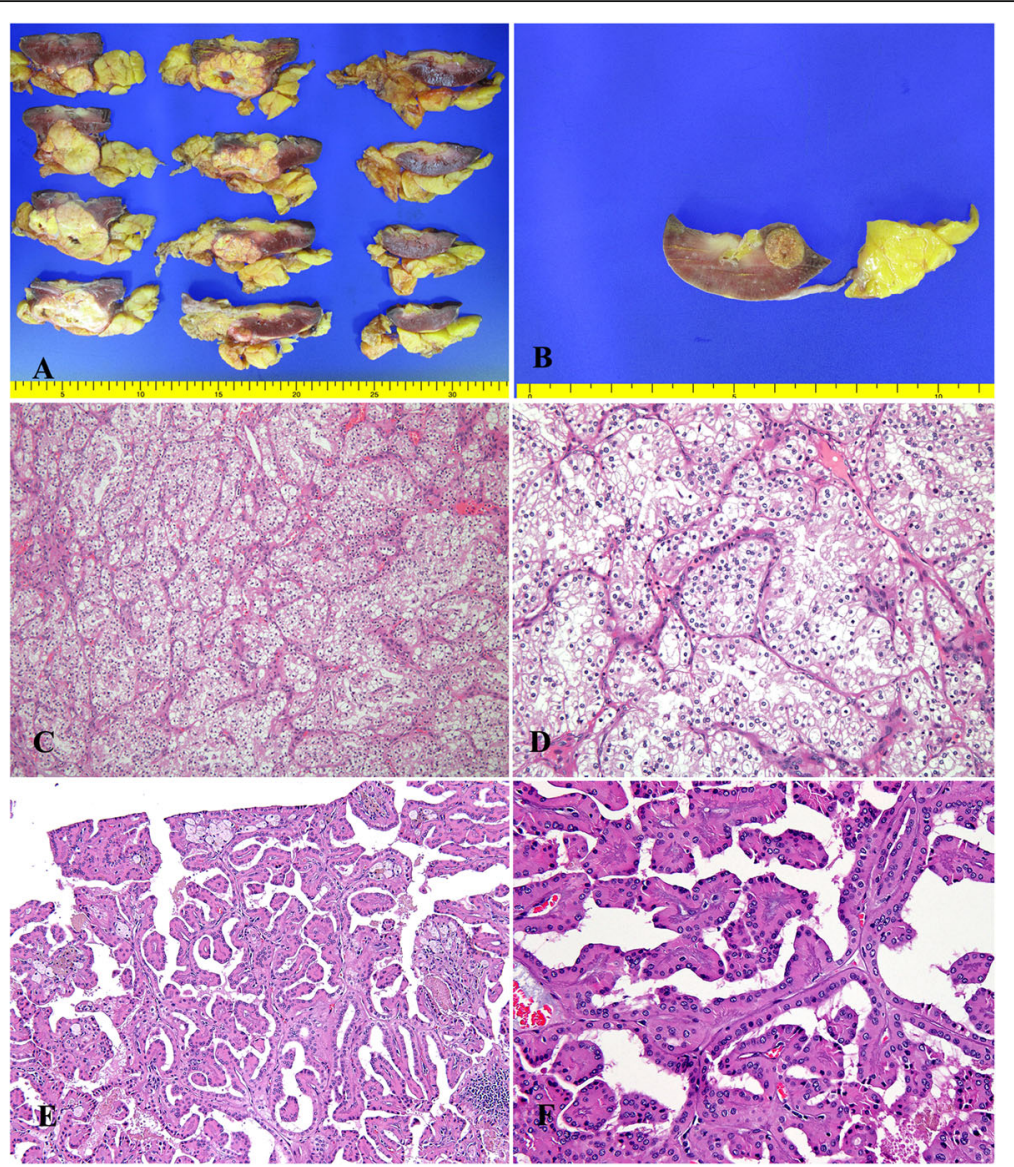

Fig. 1 The cut surface of the mass was bright golden yellow with areas of gray-white fibrosis and hemorrhage (a). A separate small nodule was present in the lower pole, measuring $1.2 \times 1.0 \times 0.6 \mathrm{~cm}$ (b). Microscopic findings of clear cell renal cell carcinoma (c). High-power view of clear cell renal cell carcinoma (d). Microscopic findings of papillary renal neoplasm with reverse polarity (PRNRP) (e). High-power view of PRNRP (f)

\section{Discussion}

Although multiple synchronous renal tumors are rare, the incidence of sporadic multifocal renal tumors at the time of diagnosis as reported in the literature is $4-20 \%$ [8-10]. This implies that observing multiple tumors in the kidney is relatively common. This is the first case to present synchronous clear cell RCC and PRNRP in the same kidney. PRNRP was first described by Al-Obaidy et al. in 2019 [4]. This study identified a PRNRP with a KRAS mutation and a cooccurring clear cell RCC with a PIK3CA mutation for the first time in the literature. The different mutation results of NGS analysis supports the biologically different diagnoses of these two synchronous renal masses.

KRAS mutations are frequently found in adenocarcinomas of the lung, colon, and pancreas [11, 12]. Varied papillary lesions, including intraductal papillary mucinous neoplasms of the pancreas and urothelial papillomas of the bladder, also have frequent KRAS mutations [13, 14]. KRAS mutations are rare events in kidney tumors, however, it has recently been found to be a characteristic feature of PRNRP as reported by multiple studies, including the current reported cases [15-17].
PIK3CA mutations are rare in clear cell RCC and are present only in $2-5 \%$ of tumors [18, 19]. PIK3CA codes for the catalytic subunit of phosphoinositide-3-kinase (PIK3), a key enzyme of the mTOR pathway; therefore, the mTOR inhibitor, everolimus, may be effective for this type of mutation.

The most common symptoms reported in RCC are hematuria in $90 \%$ of cases, flank pain in $19 \%$, and mass effect in 14\% [20]. Our patient presented with the first two symptoms. Regarding aggressiveness, clear cell RCC presents the greatest malignant potential and a 5-year survival rate of $70 \%$, while papillary and chromophobe RCCs are associated with less metastatic potential and an overall 5-year survival of 88 and 94\% [21].

Radical nephrectomy is considered the standard procedure for treating malignant renal tumors. However, recent studies show that patients with sporadic single or multiple ipsilateral renal tumors may undergo nephron-sparing surgery, with oncologically comparable results with low morbidity and recurrence rates.

Awareness of the coexistence of multiple synchronous tumors of different pathologic neoplasms in the same 


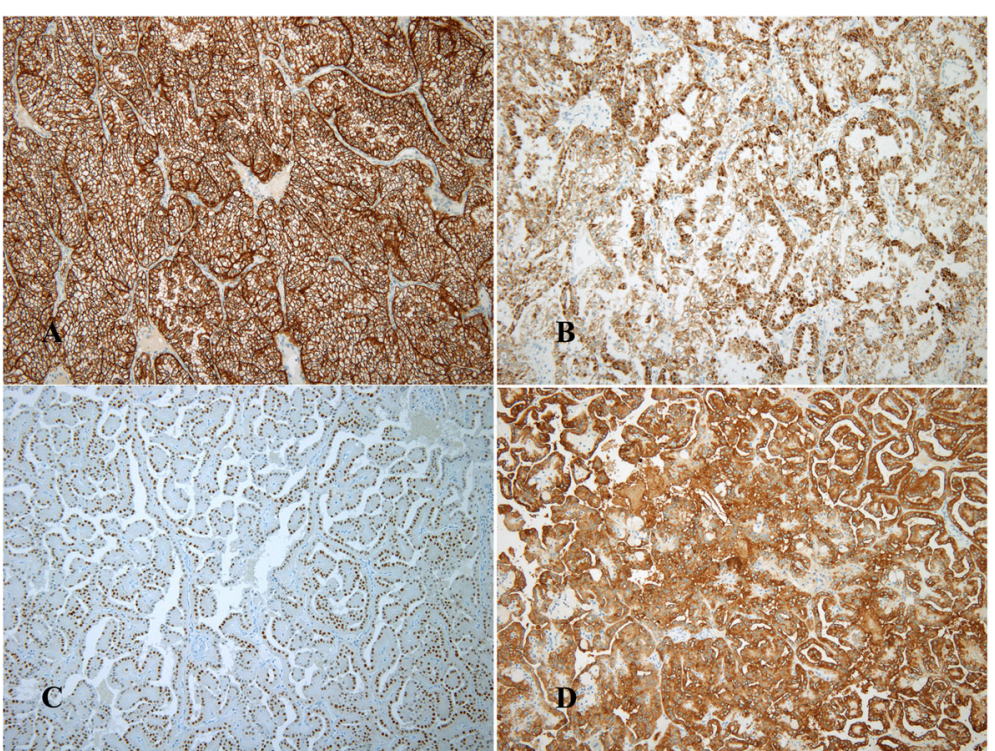

Fig. 2 Immunohistochemical stain for CAIX in clear cell renal cell carcinoma shows membranous positivity (a). AMACR shows cytoplasmic positivity in clear cell renal cell carcinoma (b). GATA3 in papillary renal neoplasm with reverse polarity (PRNRP) shows strong nuclear positivity (c). CK7 shows diffuse cytoplasmic positivity in PRNRP (d)

kidney is important for managing such cases, and nephron-sparing surgery or active surveillance may be warranted for some renal masses [22]. The fact that the pathological concordance rate is as low as $67.3 \%$ and the grade concordance rate is $62.5 \%$ [23] suggests that if a biopsy is indicated preoperatively, each nodule should be biopsied for diagnosis [8]. Different tumors will have different prognoses and degrees of aggressiveness.

There were seven cases of multiple kidney masses in Pusan National University Yangsan Hospital from March
2010 to January 2020, and Table 1 shows the characteristics of these ipsilateral multiple renal masses according to subtype. While five cases involved multiple clear cell RCCs, one presented papillary and clear cell RCCs, whereas the other had papillary RCC with metanephric adenoma. Two reports of large numbers of patients concluded that $5-6 \%$ of multiple ipsilateral renal tumors develop a contralateral metachronous recurrence and this risk is 5 times that of patients with a sporadic single tumor $[23,24]$. We suggest that multiple ipsilateral

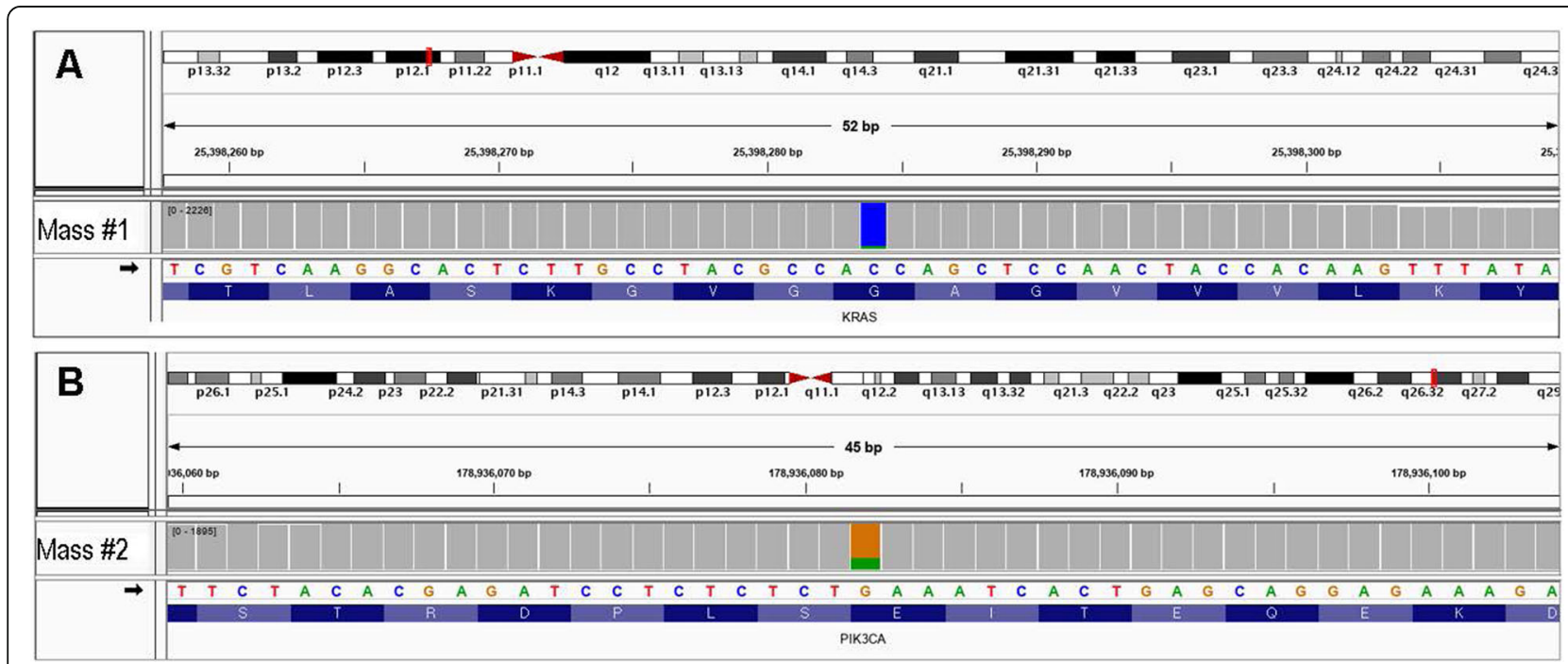

Fig. 3 Integrative Genomics Viewer (IGV) snapshot of human KRAS gene location with missense mutation identified in papillary renal neoplasm with reverse polarity. The mutation is clustered in p.Gly12Val (a). IGV snapshot of human PIK3CA gene location with missense mutation identified in clear cell renal cell carcinoma. The mutation is clustered in p.Glu542Lys (b) 
Table 1 Patient characteristics of ipsilateral multiple renal masses

\begin{tabular}{llllllll}
\hline Case & Age & Sex & Location & Tumor Size $(\mathbf{c m})$ & TNM & Grade & Histologic subtypes \\
\hline 1 & 64 & M & Right & 4.0 & pT1aNOM0 & 2 & papillary RCC, type I/ metanephric adenoma \\
2 & 53 & M & Right & 5.3 & pT1bNOM0 & 2 & clear cell RCC/ clear cell RCC \\
3 & 66 & F & Right & 2.5 & pT1aNOM0 & 2 & Clear cell RCC/ clear cell RCC \\
4 & 65 & M & Left & 4.6 & pT3aNOM0 & 2 & Clear cell RCC/ clear cell RCC \\
5 & 57 & M & Right & 2.5 & pT1aNOM0 & 3 & Clear cell RCC/ clear cell RCC \\
6 & 77 & M & Right & 4.9 & pT1bNOMO & 3 & Clear cell RCC/ clear cell RCC \\
7 & 62 & M & Left & 5.6 & pT3aNOMO & 3 & Clear cell RCC/ Papillary RCC, type II \\
\hline
\end{tabular}

synchronous RCCs of different histologic subtypes need to be followed closely and operations for each mass are necessary. The frequency of clinical multifocality is consistent with reported local recurrence rates following partial nephrectomy. The impact of tumor multifocality on patient survival is controversial; however, each nodule should be evaluated for an accurate prognosis.

In summary, we report the first unusual case of unilateral synchronous PRNRP with a KRAS mutation (c.35G > T/p.G12V in exon 2) and clear cell RCC with a PIK3CA mutation (c.1624G > A/p.E542K in exon 10).

\section{Abbreviations}

NGS: Next-generation sequencing; RCC: Renal cell carcinoma; ISUP: International Society of Urological Pathology; PRNRP: Papillary renal neoplasm with reverse polarity; HMW: High-molecular-weight; H\&E: Hematoxylin and eosin; IGV: Integrative Genomics Viewer

\section{Acknowledgements}

Not applicable.

\section{Authors' contributions}

The report was designed, written, and reviewed by Hyun Jung Lee under the supervision of Dong Hoon Shin, Jee Yeon Kim and Mee Young Sol. All authors contributed to the data collection, data analysis, and interpretation. The manuscript was approved by all authors.

\section{Funding}

This study was supported by Research institute for Convergence of biomedical science and technology (20-2019-003), Pusan National University Yangsan Hospital.

\section{Availability of data and materials}

The dataset supporting the conclusions of this article is included within the article.

\section{Ethics approval and consent to participate}

This study was approved by the Institutional Review Board of the Pusan National University Yangsan Hospital (no. 05-2020-173).

\section{Consent for publication}

Not applicable.

\section{Competing interests}

The authors declare no competing interests.

\section{Author details}

'Department of Pathology, School of Medicine, Pusan National University, Yangsan, Korea. ${ }^{2}$ Research Institute for Convergence of Biomedical Science and Technology, Pusan National University Yangsan Hospital, Yangsan, Korea. ${ }^{3}$ Department of Urology, School of Medicine, Pusan National University, Yangsan, Korea.
Received: 28 August 2020 Accepted: 30 September 2020

Published online: 06 October 2020

References

1. Siegel RL, Miller KD, Jermal A. Cancer statistics. CA Cancer J Clin. 2016;66:730.

2. Cohen HT, McGovern FJ. Renal cell carcinoma. N Engl J Med. 2005;353: 2477-90.

3. Delahunt B, Eble JN. Papillary renal cell carcinoma: a clinicopathologic and immunohistochemical study of 105 tumors. Mod Pathol. 1997:10:537-44.

4. Al-Obaidy Kl, Eble JN, Cheng L, et al. Papillary renal neoplasm with reverse polarity: a morphologic, immunohistochemical, and molecular study. Am J Surg Pathol. 2019;43:1099-111.

5. Patel MI, Simmons R, Kattan MW, Motzer RJ, Reuter VE, Russo P. Long-term follow-up of bilateral sporadic renal tumors. Urology. 2003;61:921-5.

6. Klatte T, Wunderlich H, Patard JJ, et al. Clinicopathological features and prognosis of synchronous bilateral renal cell carcinoma: an international multicentre experience. BJU Int. 2007;100:21-5.

7. Billings B, Hamrick LC, Bueschen AJ, Kenney PJ. Coexisting angiomyolipoma and renal cell carcinoma in a kidney of an elderly woman: case report and review of the literature. Sci World J. 2004:4:27-30.

8. Alhusban M, Alhamss S, Alzumaili B, Al-Daghmin A. Ipsilateral synchronous clear and papillary renal cell carcinoma: A case report and review of the literature. Urol Case Rep. 2017;16:110-3.

9. Dimarco DS, Lohse CM, Zincke H, Cheville JC, Blute ML. Long-term survival of patients with unilateral sporadic multifocal renal cell carcinoma according to histologic subtype compared with patients with solitary tumors after radical nephrectomy. Urology. 2004;64:462-7.

10. Richstone L, Scherr DS, Reuter VR, et al. Multifocal renal cortical tumors: frequency, associated clinicopathological features and impact on survival. J Urol. 2004;171:615-20.

11. Eberhard DA, Johnson BE, Amler LC, et al. Mutations in the epidermal growth factor receptor and in KRAS are predictive and prognostic indicators in patients with non-small cell lung cancer treated with chemotherapy alone in combination with erlotinib. J Clin Oncol. 2005;23:5900-9.

12. Amado RG, Wolf $M$, Peeters $M$, et al. Wild-type KRAS is required for panitumumab efficacy in patients with metastatic colorectal cancer. J Clin Oncol. 2008;26:1626-34.

13. Mohri D, Asaoka Y, ljichi $H$, et al. Different subtypes of intraductal papillary mucinous neoplasm in the pancreas have distinct pathways to pancreatic cancer progression. J Gastroenterol. 2012:47:203-13.

14. Isharwal S, Hu W, Sarungbam J, et al. Genomic landscape of inverted urothelial papilloma and urothelial papilloma of the bladder. J Pathol. 2019; 248:260-5.

15. Al-Obaidy Kl, Eble JN, Nassiri M, et al. Recurrent KRAS mutations in papillary renal neoplasm with reverse polarity. Mod Pathol. 2020;33:1157-64.

16. Kim SS, Cho YM, Kim GH, et al. Recurrent KRAS mutations identified in papillary renal neoplasm with reverse polarity-a comparative study with papillary renal cell carcinoma. Mod Pathol. 2020;33:690-9.

17. Tong $\mathrm{K}$, Zhu W, Fu H, et al. Frequent KRAS mutations in oncocytic papillary renal neoplasm with inverted nuclei. Histopathology. 2020;76:1070-83.

18. Creighton CJ, Morgan M, Gunaratne PH, et al. Comprehensive molecula characterization of clear cell renal cell carcinoma. Nature. 2013;499:43-9.

19. Sato $Y$, Toshizato $T$, Shiraishi $Y$, et al. Integrated molecular analysis of clear cell renal cell carcinoma. Nat Genet. 2013:45:860-7. 
20. Benavides-Huerto MA, Chávez-Valencia V, Lagunas-Rangel FA. Synchronous renal neoplasm: clear cell renal cell carcinoma and papillary urothelial carcinoma in the same kidney. Urol Case Rep. 2017;11:60-2.

21. Amin MB, Tamboli P, Javidan J, et al. Prognostic impact of histologic subtyping of adult renal epithelial neoplasm-an experience of 405 cases. Am J Surg Pathol. 2002;26:281-91.

22. Blute M, Thibault GP, Leibovich BC, Cheville JC, Lohse CM, Zincke H. Multiple ipsilateral renal tumors discovered at planned nephron sparing surgery: importance of tumor histology and risk of metachronous recurrence. J Urol. 2003;170:760-3.

23. Beaugerie $A$, Audenet $F$, Verkarre $V$, et al. Pathological heterogeneity in sporadic synchronous renal tumors: is the histological concordance predictable? Uorl Oncol. 2018;36:11.e7-12.

24. Minervini A, Serni S, Giubilei G, et al. Multiple ipsilateral renal tumors: retrospective analysis of surgical and oncological results of tumor enucleation vs radiacal nephrectomy. Eur J Surg Oncol. 2009;35:521-6.

\section{Publisher's Note}

Springer Nature remains neutral with regard to jurisdictional claims in published maps and institutional affiliations.

Ready to submit your research? Choose BMC and benefit from:

- fast, convenient online submission

- thorough peer review by experienced researchers in your field

- rapid publication on acceptance

- support for research data, including large and complex data types

- gold Open Access which fosters wider collaboration and increased citations

- maximum visibility for your research: over $100 \mathrm{M}$ website views per year

At BMC, research is always in progress.

Learn more biomedcentral.com/submissions 